The influence of maternal psychopathology on ratings of child psychiatric symptoms: An SEM analysis on cross-informant agreement

Jörg M. Müller, Sandra Achtergarde and Tilman Furniss

Department of Child and Adolescent Psychiatry, Psychosomatics and Psychotherapy University Hospital Muenster, Germany

Prof. Tilman Furniss, MD, MPhil, FRCPsych

Dep. of Child and Adolescent Psychiatry

University Hospital Münster

Schmeddingstrasse 50

48149 Münster, Germany

E-Mail: furniss@uni-muenster.de 


\begin{abstract}
The distorting influence of maternal depression on the ratings of child behaviour is known as the depression-distortion hypothesis. This study investigated the depression-distortion hypothesis in a clinical sample of child psychiatric preschool children and extended the depression-distortion-hypothesis to maternal psychopathology-distortion-hypothesis in general. Subjects were 124 children, who were referred for treatment in a Child Psychiatric Family Day Hospital for preschool children, and their parents. Children were rated on the CBCL/1.5-5 and the C-TRF/1.5-5 by their mothers, kindergarten teachers and therapists. Maternal psychopathology was assessed by self-rating with the SCL-90-R and the BDI. The appropriateness of the depression-distortion hypothesis, as well as two alternatives, the accuracy and the combinatory model, were subsequently analyzed by structural equation modelling (SEM), including the ratings of all three informants. Model fit and parameter estimation supported the distortion model, suggesting that ratings of child behaviour by mothers may be biased by maternal psychopathology. Findings are discussed with regard to the existing cross-informant literature, with particular consideration of the distortion hypothesis and third person ratings of child psychopathology in preschool age.
\end{abstract}

\title{
Keywords
}

Preschool children, depression-distortion-hypothesis, cross-informant agreement, CBCL, structural equation modelling. 


\section{The influence of maternal psychopathology on ratings of child psychiatric symptoms: An SEM analysis on cross-informant agreement}

\section{Introduction}

In the assessment of emotional and behavioural psychiatric symptoms in preschool children, the procedure of collecting and combining information from multiple sources, e.g. mother, father, therapist, kindergarten teacher, or foster parent, has become the standard of practice $[3,55]$. However, research has consistently shown that the agreement between ratings of child behaviour by different informants is only low to moderate [14, 30, 43, 50, 62, 64, 72]. Although most of these studies have considered school-age children, there are also examples of cross-informant studies with preschool samples, reporting similar results [39, 42, 68].

Attempts to explain the general lack of agreement among informants have included among other reasons the personal characteristics of the informant (e. g. age, gender, social function, psychopathology), tendencies to simulate or dissimulate, use of different reference groups, characteristics of the child who is rated, and situation-specific behaviour [21, 54]. The present study focuses on the influence of maternal psychopathology on the symptoms and behaviour ratings of their clinical referred preschool age children. This factor is of particular importance, as usually mothers are the most important source of information about their child's psychiatric symptoms [51].

In general, mentally ill people, particularly when they are depressed, tend to view other people and their behaviour more negatively than healthy people [48]. This observation has led to the depression-distortion-hypothesis or distortion model [57]. The distortion model assumes that the cognitive and perceptual distortions, which are associated with psychiatric disorders, may affect maternal ratings of their children's behaviour (a more generalized model is described by the Attribution Bias Context model, [21]). The distortion assumption has been supported in previous studies with non-clinical and at-risk samples of children and 
adolescents and their mothers [14, 26, 28, 47, 74, 75] and clinical referred children [18, 27, $35,40,41,45]$, while no studies were found for clinical referred preschool children. Such samples are especially of interest for two reasons. First, the often-applied clinical instruments assessing psychopathology in parents or children are designed for clinical samples. Second, we expect especially in preschool psychiatry a greater variation of child and parental psychopathology, which is a precondition to observing a substantial true covariation between maternal and child psychopathology.

For example children of psychiatrically ill mothers show actually more symptomatic behavior then the children of healthy mothers $[15,52]$. Maternal psychopathology appears therefore to be related to actual child psychopathology by means of genetic transmission, social learning processes, lack of maternal sensitivity, insecure attachment patterns, or inadequate or inconsistent parenting behaviour [31, 44, 49, 52, 65]. Higher maternal ratings may therefore also reflect a truly higher level of mental health symptoms in their children. This alternative assumption has been called the accuracy model [57]. Especially in the context of a child psychiatric preschool population and related nosological approaches [53, 63, 76], a reciprocal relationship between maternal and child symptom levels appears plausible. Children with an increased level of psychopathology or regulatory disorders may cause an increased psychopathology in their mothers [71]. Furthermore, the German Society of Child and Adolescent Psychiatry, Psychosomatics and Psychotherapy [29] consider a regulatory disorder as a symptom triad of infant behavioural problems, severe parental distress and dysfunctional interaction processes between parents and child.

Finally, maternal ratings of child psychiatric symptom behaviour might be influenced simultaneously by pathologic distortions by the mother and by a truly increased level of child psychiatric symptom behaviour in their children. This model, which would predict mixed results, will henceforth be referred to as combinatory model. The assumptions of the combinatory model have been supported in some studies with school-age children [15, 19]. 


\section{Aims of the present study}

We will describe cross-informant agreement on child mental health symptom ratings by mothers, teachers and therapist, addressing two aspects: discrepancies in the absolute degree of reported symptom behavior, and the correspondence (correlations) between crossinformant ratings. Both aspects have to be examined separately, as they may lead to different conclusions. With regard to correspondence, we assume that correlations between ratings of parents, kindergarten teachers and therapists will be low to moderate, according to the results of previous research as described above. With regard to discrepancies, we expect that mothers will report more problem behaviour than the other groups of informants, as has been shown in previous studies.

Considering the potential influence of maternal psychopathology on child behaviour ratings, we will compare the distortion, the accuracy, and the combinatory model by structural equation modelling (SEM). In SEM, the accuracy model will be tested by a direct association (path) between maternal psychopathology and child psychopathology (which are both considered to represent latent variables). The distortion model will be tested by a direct association (path) between maternal psychopathology and maternal ratings of child psychopathology, which is considered as one observed indicator of child psychopathology. The combinatory model, however, postulates the coexistence of both paths. The full description of the definition of the three models will be given below.

\section{Methods}

\section{Procedure}

This study was conducted as part of a more comprehensive evaluation at the Psychiatric Family Day Hospital for Infants and Preschool Children and their Parents of the Department of Child and Adolescent Psychiatry, University Hospital Münster, Germany. The Family Day Hospital treats child psychiatrically ill preschool children between zero and six years and their parents, whenever necessary. The application of a standardized child psychiatric behaviour rating is part of the routine assessment procedure on admission. 
The present study includes 124 preschool children who were successively referred as child psychiatric patients to the Family Day Hospital. Only one child per family was included in this analysis in order to avoid confounding effects. On admission to the Child Psychiatric Family Day Hospital, all accompanying mothers completed the SCL-90-R, the BDI and the Child Behavior Checklist for the Preschool Age (CBCL/1.5-5). Children's kindergarten teachers were asked to complete the Caregiver-Teacher Report Form at Preschool Age (C-TRF). In addition, all preschool patients were rated by their therapist from the Family Day Hospital on the C-TRF. The cross informant syndrome scores, which were used in this study, were derived from the CBCL- and C-TRF scores.

Subjects

\section{Children}

Of the 124 children who were included in the study, 89 were boys $(71.8 \%)$. Mean age of the children was 3.94 years $(S D=1.63)$. Note, that school entry in Germany is set at age six. The majority of the children (99.2\%) were German; one child came from another EU country. Most of the children (78.2\%) lived with both parents; 26 children (21.0\%) lived in a singleparent family. The children had no sibling in 45 (36.3\%) cases, 60 (48.4\%) children had one sibling, and 19 (15.3\%) children had two or more siblings.

\section{Mother}

Maternal age ranged from 19 to 49 years with a mean of $M=33.32$ years $(S D=5.69$ ). Information about school education was available from 86 mothers. Of those, 22 (17.7\%) had completed 12-13 years of grammar school education leading to university entrance, 29 (23.4\%) had completed 10 years of secondary modern school education and $31(25.0 \%)$ had completed 9 years of secondary school. A substantial percentage of the mothers $(44.4 \%)$ attended the Child Psychiatric day Hospital not only as an accompanying person to their psychiatrically ill child, but were also diagnosed as suffering from psychiatric illness themselves and received psychiatric treatment in the Family Day Hospital [8]. Due to privacy protection, information about the kindergarten teachers and therapists who participated in the study was not recorded. 
Measures

ASEBA

The Achenbach System of Empirically Based Assessment (ASEBA) [3, 55] is a set of instruments which have been designed to assess child symptoms from the perspective of multiple informants. The ASEBA includes, among other instruments, the CBCL questionnaire for parents, and the C-TRF for teachers, kindergarten teachers, caregivers, diagnosticians and therapists. The CBCL and C-TRF versions for children between 1.5 and 5 years are frequently used in clinical assessment and research on preschool children with mental health disorders $[13,16,20]$.

CBCL/1.5-5 and C-TRF/1.5-5

Children were rated on the Child Behavior Checklist for the Preschool Age (CBCL/1.5-5) and the Caregiver-Teacher Report Form for the Preschool Age (C-TRF/1.5-5) [3, 6]. CBCL/1.5-5 and C-TRF/1.5-5 consist of 100 problem items each, which are rated by parents or caretakers, respectively, on a 3-point-scale $(0=$ "not true" to $2=$ "very true or often true"). A large proportion of all items (80\%) are common to both questionnaires and build the socalled cross-informant syndrome scales, which will be described below. The psychometric qualities of the CBCL/1.5-5 and CTRF/1.5-5 have been confirmed in various studies [14, 73]. Above all, the Total Problems score seems to be relevant as a general indicator of clinical relevant psychopathology in young children [38]. Therefore, the SEM analyses conducted in this study will rely on the Total Problems scores of the CBCL/1.5-5 and CTRF/1.5-5. A Total Problem score is available in three scale metrics. Raw scores are recommended for research purposes excluding cross-informant studies. T-scores are recommended for clinical purposes, which take different thresholds of informants into account and adjusted mean and variance score differences by norm-tables. Cross-informant scores are recommended for cross-informant studies, but do not take different thresholds of informants into account.

Cross-Informant Syndrome-Scales

The use of the cross-informant syndrome scales is appropriate in cross-informant comparison studies, in order to ensure that differing item content is not reducing agreement 
[67]. The cross-informant syndrome scales of the CBCL/1.5-5 and the C-TRF/1.5-5 include the following empirically based syndrome scales: Emotionally Reactive (7 items), Anxious/Depressed (8 items), Somatic Complaints (7 items), Withdrawn (8 items), Attention Problems (5 items), and Aggressive Behaviour (19 items). The scales Emotionally Reactive, Anxious/Depressed, Somatic Complaints, and Withdrawn can be combined to give the Internalizing broadband scale. The scales Attention Problems and Aggressive Behaviour are combined to give the Externalizing broadband scale. Additionally 26 items do not constitute a separate consistent scale and are subsumed under Other Problems. The Total Problems scale includes the complete set of 80 items. Consequently, the cross-informant syndrome scales are very similar to the syndrome scales of CBCL and C-TRF, with the exception of the syndrome scale Sleep Problems. This scale is not present in the C-TRF and therefore not included in the cross-informant syndrome scales.

SCL-90-R

Mothers completed the Symptom Checklist-90-Revised (SCL-90-R) [22], a well-established self-report inventory aimed to assess psychopathology in adults. The instrument consists of 90 items which measure psychological and psychosomatic symptoms during the last seven days. Subjects rate each item on a 5 -point Likert scale $(0=$ "no problem" to $4=$ "very serious"). The questionnaire yields scores on nine specific dimensions (Somatization, Obsessive-Compulsive, Interpersonal Sensitivity, Depression, Anxiety, Hostility, Phobic Anxiety, Paranoid Ideation and Psychoticism) and three global scores (Global Severity Index, Positive Symptom Distress Index, and Positive Symptom Total). However, current international studies have questioned the validity of the subscales and strongly recommend the use of the Global Severity Index (GSI) as an index of general psychopathology [34, 67]. Subjects who exceed a cut-off score (GSI .57) are considered to exhibit psychiatric symptoms to a clinically relevant degree [60].

$B D I$

The Beck Depression Inventory [9, 10, 33] is an internationally accepted and widely used measure of the severity of depression in adult subjects. The questionnaire was included in 
this study because depressive symptoms are one of the most common forms of psychopathology among women. The BDI is useful to assess not only severe depression, but also milder forms of dysphoria [75]. The self-report questionnaire consists of 22 groups of items and yields one global score. Subjects are asked to choose one item out of a group which describes best how they have felt during the last seven days. Items have been selected following DSM diagnostic criteria for major depression. Reliability and validity of the instrument have been proven in numerous studies (for a review on studies of the German version see Richter et al. 1998 [56]).

Data analysis

Statistical analysis in this study was based on raw scores of the cross-informant syndrome scales, as raw scores reflect the actual distributions of the extent of symptom behavior and should be favoured for statistical analysis of the CBCL/1.5-5 and CTRF/1.5-5 [3]. T-scores were used to describe the clinical referred sample of children. Pearson product moment correlations were calculated to examine the correspondence between informants on CISscores. Paired t-tests were conducted in order to reveal discrepancies in the severity of ratings.

To overcome the shortcomings of testing singular aspects of the accuracy, distortion, or combinatory model, we applied structural equation modelling to directly and simultaneously compare all aspects of the underlying hypothetical models with each other. We defined three structural equation models (SEM) to represent the accuracy, distortion, or combinatory model similar to previously defined models $[15,26,28]$. The underlying hypothetical models are then compared, which provides the best explanation for variance in mothers', teachers' and therapists' ratings by overall and comparative model-fit indices and significance of path coefficients. The SEM analysis focused on the broadband scale Total Problems scores of the CBCL/1.5-5 and CTRF/1.5-5, as this scale has been shown to be especially predictive of child psychopathology [38]. Model specification will be described below in more detail. The 
model was defined and the analysis was conducted with the structural equation modelling program AMOS 8.0 [7].

To use all available data for analysis, AMOS 8.0 estimates structural equation by maximum likelihood methods for handling missing data in an optimal fashion [5]. However, missing data may produce a sampling error, which puts the validity of findings in question. Therefore, to test if the $21.3 \%$ missing data over all scales are not related to observed values, dummy variables were created for each of the five measures (SCL-90-R, BDI, CBCL/1.5-5 from mother, and CTRF/1.5-5 from teacher, therapist) with a ' 1 ' in case of missing data, and ' 0 ' if observed data are available. These five dummy variables were used as class variables for ttests with the remaining four scales as dependent variables to check for the missing at random condition and from 20 tests one was significant $(p>.05)$ and none after Bonferonie correction. Statistical analysis was conducted with the Predictive Analysis Software, PASW 18.0.0 (formerly Statistical Package for the Social Sciences, SPSS).

\section{Results}

Sample preconditions to study the distortion model

For subsequent testing of the distortion model, the sample preconditions should include a considerable variation in maternal psychopathology and in child psychopathology. Children show a maternal mean T-score of $M=60.32(S D=22.58)$, and with respect to a cut-off of 60, 53.8\% show in CBCL Total Problem score a relevant degree of psychopathology. Mothers' mean SCL-90-R Global Severity Index was $M=0.71(S D=0.44)$ and score of 0.57 or above indicates mental distress to a clinically relevant degree, which applied to $54.9 \%$ mothers in our study. The maternal mean BDI sum score was $M=14.70(S D=8.76)$.

Child symptom behaviour ratings by mothers, teachers and therapists

\section{Cross-informant correspondence}

Cross-informant agreement (correspondence) between parents, teachers, and therapists was generally moderate. Cross-informant correlations were higher for Externalizing 
symptoms than for Internalizing symptoms in mothers and teachers $\left(r_{\text {Ext }}=.54, p<.001\right.$ vs. $r_{\text {Int }}$ $=.36, \mathrm{p}<.001)$, mothers and therapists $\left(r_{E x t}=.39, p<.001\right.$ vs. $\left.r_{I n t}=.09, n . s.\right)$ and teachers and therapists $\left(r_{E x t}=.51, p<.001\right.$ vs. $r_{I n t}=.04, n . s$. $)$. The agreement between mothers and teachers on Total Problems was significant $\left(r_{\text {Tot }}=.38, p<.001\right)$, while there was no significant correlation between mothers and therapists or between teachers and therapists, respectively.

\section{Cross-informant discrepancies}

Over all scales of analysis, mothers gave higher ratings then teachers, who gave higher ratings then therapist, albeit that the difference in the teacher-therapists comparison was not significant. On the level Total Problem scores and both broadband scales (see Table 1), mothers' ratings of child behaviour were significantly higher than teachers ratings on Internalizing symptoms, Externalizing and Total Problems. Mothers' ratings of child symptoms behaviour were also significantly higher than therapist ratings on Internalizing symptoms, Externalizing symptoms, and Total Problem scores. Therapists' and teachers' ratings did not differ significantly from each other on the broadband scales.

-> Insert Table 1 about here

\section{SEM analysis}

Scale properties and intercorrelation between SCL and CBCL scores

Prior to reporting the SEM results, it is good practice to also report the scale properties and the underlying correlation matrix of indicators (observed variables: SCL-90-R Global Severity Index, BDI sum score, CBCL Total Problems, C-TRF Total Problems by Teacher, C-TRF Total Problems by Therapist) of the latent variables (maternal psychopathology, child psychopathology) in SEM [32]. The internal consistency of all scales (Table 2) was good to excellent, with Cronbach's alpha between .86 and .96. The intercorrelation matrix (Table 2) reveals a significant correlation between BDI and SCL scores. Cross-informant syndrome Total Problem scores rated by mothers correlated significantly with BDI and SCL scores. 
The structural equation models (Fig. 1) are based on the assumptions derived from the accuracy, distortion, and combinatory model about the association between maternal psychopathology, child psychopathology, and the maternal rating. We hypothesized that the observed Total Problems scores by mother, teacher, and therapist load on the latent factor 'Child Psychopathology'. Second, we assumed that the observed BDI sum score and SCL90-R Global Severity Index load on the latent factor 'Maternal Psychopathology'. Third, we assumed that the latent factor 'Maternal Psychopathology' had an impact on maternal rating, either directly (according to the distortion model; subsequently thereafter referred to as the distortion path), or indirectly over the latent factor 'Child Psychopathology' (according to the accuracy model; subsequently thereafter referred to as the accuracy covariation), or through a combination of both (combinatory model). Importantly, the combinatory model includes both paths representing an association between maternal psychopathology and child outcome: the 'distortion' path and 'accuracy' covariation. Therefore, the other models can be viewed as subsets, or nested models, of the combinatory model, and they can be directly compared to the combinatory model with regard to model fit [17].

In order to retain degrees of freedom and achieve overidentification of the models, error variances of observed variables corresponding to the same latent parameter and instrument were constrained to be equal (Fig. 1). Such constraints can be justified by approximately comparable internal consistencies (Table 2), which indicate a comparable measurement error. Parameters were estimated and fit indices calculated separately for each model, implementing the method of maximum likelihood estimation. As well as the model fit-indices, additionally the significance of parameter estimates for single paths or covariance are taken into consideration when rejecting or retaining a model.

-> Insert Figure 1a,b,c about here

\section{Parameter estimates}

Figure 2 shows the standardized regression weights (SRW; path coefficients or covariance). The measurement model of maternal psychopathology and child psychopathology show only significant indicators for the distortion and the combinatory model, while for the accuracy 
model, the path 'Child Psychopathology' 'Total Problem Therapist' fails on significance and indicates to rejection of the accuracy model.

The models differ predominantly with regard to the 'accuracy' covariation and the 'distortion' path. The distortion path was significant in the distortion model $(\mathrm{SRW}=.40 ; \mathrm{p}<.001)$ and in the combinatory model (SRW $=.38, \mathrm{p}<.001$; see Fig. 2$)$. In the accuracy model the 'accuracy' covariance was freely estimated and was high and significant (SRW $=.40, p<$ $.001)$. In the combinatory model, this coefficient was low and insignificant (SRW $=.06, \mathrm{n} . \mathrm{s}$.) and indicates to rejection of the combinatory model. In summary, the parameter estimates support only the distortion and not the accuracy or the combinatory model and closer examination of the measurement models indicates a measurement problem in the accuracy model. Moreover, a model misspecification (omission of a distortion path) lead to a superficial substantial covariation between maternal and child psychopathology in the accuracy model. In order to assure that the covariation between maternal and child psychopathology does not reflect a substantial effect we estimated the accuracy model again without maternal rating and observed a non-significant covariation of SRW $=-.04$ as recommended by one reviewer.

-> Insert Figure 2a,b,c about here

\section{Overall model fit}

The AMOS programme offers a host of fit indices representing the fit of structural equation models. According to recommendations from the current literature $[17,61]$, we selected the

Chi-square statistic $\left({ }^{2}\right)$, the Comparative Fit Index (CFI), and the Root Mean Square Error of Approximation (RMSEA) as measures of overall fit, and the Akaike Information Criterion (AIC) as comparative measure of fit and parsimony (Table 3).

-> Insert Table 3 about here

Structural equation models are considered to fit the data well when the test of the Chi-square statistic is non-significant, the ratio of the estimated Chi-square statistic to the degrees of freedom is less than three [72] and the CFI is close to .95 [37] or .97 [61]. The RMSEA [24, 25] represents adequate fit when scores are below .08 [17]. With respect to the selected fit 
indices, the distortion and the combinatory models fit the data quite well (Table 3). In contrast, the accuracy model yields lower values $(\mathrm{CFI}=.91$; RMSEA $=.10)$ which suggest that the model should be rejected [61].

Comparison of model fit

As the accuracy model and the distortion model are nested models of the combinatory model, both can be directly compared to the combinatory model with regard to the ${ }^{2}$-statistic, following the formula by Bentler [11]. The resulting difference between the ${ }^{2}$-values of the accuracy and the combinatory model is significant on the level of $p<.05\left({ }^{2}(1)=9.55\right)$, which indicates that the fit of the two models differs significantly [17]. In this case, the less restricted model (here the combinatory model) should be retained [61], because the combinatory model fits better. The second model check compares the difference between the ${ }^{2}$-values of the distortion and combinatory model, which is very small and insignificant ( $\left.{ }^{2}(1)=0.10\right)$ which means that both models fits are equal. In such cases, the more restricted model (here the distortion model) should be favoured [61], because it need fewer parameters to fit the data. As the distortion model and the accuracy model are not nested, they cannot be compared with regard to the ${ }^{2}$-statistic. However, the models can be compared on the basis of descriptive model fit indices, for example the Akaike Information Criterion (AIC) [4, 61]. The AIC addresses parsimony as well as model fit. It is used in the comparison of two or more models, with lower values indicating better fit [36]. According to this index (Table 3), the distortion model yields the best value $(\mathrm{AIC}=32.26)$, followed by the combinatory model (AIC $=34.16)$ and finally the accuracy model $(\mathrm{AIC}=41.71)$. In summary, all indicators of model fit consistently favour the distortion model, which explains the variance of maternal rating of child psychopathology in total by $38.4 \%$, with $55.27 \%$ explained by child psychopathology, and $44.73 \%$ explained by maternal psychopathology. Maternal rating of child psychopathology is therefore substantially driven by maternal psychopathology. 


\section{Discussion}

We considered the potential effect of maternal psychopathology on mothers' symptom behaviour ratings compared to kindergarten teachers' and therapists' ratings of pre-school children referred to the Family Day Hospital of the Child Psychiatric Unit of the University Münster. In general, cross-informant correspondence between mothers, kindergarten teachers, and therapists of mental health symptoms in our study was low to moderate. Correspondence between mothers and teachers was higher than between mothers and therapists, or teachers and therapists, with higher agreement on Externalizing than on Internalizing symptom scores. These findings are consistent with the results of many other studies on cross-informant agreement on the ASEBA scales [2, 14, 23, 42, 69]. Our main result on discrepancy, namely that mothers reported more symptomatic problem behaviour than kindergarten teachers and therapists, is also in line with the existing literature $[40,69]$. In the analysis, we focussed on two explanations for the observed increased maternal scale scores: the distortion and the accuracy model. The distortion model postulates exaggerated ratings of highly distressed mothers, while the accuracy model states that these ratings reflect the actually heightened level of problem behaviour in the children of distressed mothers [57, 75].

In order to compare both models directly with each other, and additionally with a third model which combined both theoretical explanations ("combinatory model"), we followed a structural equation modelling approach and defined three structural equation models (Fig. 1). Note, that our model specifications differ slightly from other structural equation testing of the distortion model $[26,28]$, as the path from maternal psychopathology end at mother's rating, and not at the residual term of mother's rating to focus on rating error caused by maternal psychopathology. The reason was mainly of a theoretical nature. We consider maternal ratings of child psychopathology also as a potential indicator of maternal psychopathology. Additionally, we achieved a more parsimony model by saving one parameter, which allowed testing of the model with smaller sample size. Additional computations following the alternative model specification from Gartstein [28] replicated our findings. 
Results of the analysis (Fig. 2, Table 3) suggested favouring the distortion model, which obtained the best model fit and parsimony indices. Path and covariation coefficients revealed the significant influence of maternal psychopathology on mothers' behaviour ratings. Our findings are consistent with the results of recent studies $[15,26,47,66,75]$ found that caregiver depressive symptoms proved to be one of the most important predictors of crossinformant disagreement, which is consistent with the distortion hypothesis. Comparably, Najman et al. [47] found that anxious and/or depressed mothers reported more child behaviour problems than healthy mothers or the (14-year-old) children themselves. Treutler and Epkins [66] extended their analysis to fathers, and observed that both parents' psychological symptoms were significantly related to their ratings of children's internalizing and externalizing behaviour. Taken together, there is substantial empirical evidence for the validity of the distortion model; moreover, there is increasing evidence that it may be appropriate to extend the distortion hypothesis from depression to general psychopathology $[47,21,19,75]$. This issue needs to be investigated more thoroughly in further studies across instrument and maternal and child psychopathology, accompanied with expert ratings of maternal psychopathology to rule out a general response bias to reporting of own and other symptoms [26].

In addition to the evidence supporting the distortion bias, we also observe that ignoring a distortion influence has led to problems in the measurement model of the accuracy model. Ignoring the distortion path impedes agreement between maternal report, teacher, and therapist. Interestingly, we observed on a descriptive level a slightly negative correlation between indicators of maternal psychopathology and therapist rating of child psychopathology (see Tab. 1). This raises the question, of whether experienced therapists, who have been in contact with the mother (in contrast to teachers), over proportionally counterbalance their rating of the child in cases where they consider the mother to be distressed. This would mean that the therapists already incorporate the distortion influence into their evaluation ratings by a professional heuristic. Another consequence of ignoring a distortion influence led to a substantial covariation between maternal and child 
psychopathology of SRW $=.40$. This substantial covariation can be misinterpreted in preschool psychiatry such that mothers with increased psychopathology increase the risk for psychopathology in their child or that a child with increased psychopathology increases the mother's risk for psychopathology risk for psychopathology in her mother. We did not find evidence for this interpretation. In general, our structural equation did not resolve fundamental differences between informants with respect to different thresholds (informant discrepancies, see Tab. 1) as the analysis focused on increasing the association (correspondence, see Tab. 2) between informants with respect to maternal psychopathology. Strengths and limitations

The advanced statistical methodology, which allows for the consideration of multiple factors simultaneously, is an important strength of the present study. Second, maternal and child psychopathology were assessed objectively and validly by means of well-established questionnaires with known psychometric qualities. Third, child behaviour was rated by multiple informants, which enhanced the estimation of child psychopathology in the SEM model. Finally, our clinical sample, in contrast to the majority of risk-samples taken to test the distortion hypothesis, is ideally placed to distinguish between the concurrent models as our clinical sample includes children and mothers, who differ greatly in their psychopathological status.

Yet the study has several limitations. First, being a clinical sample, the sample was selective with proportionally more boys then girls and quite small, especially with respect to the implementation of SEM. However, there is evidence that sample size may be small in simple models like ours [61]. Our sample size of $N=124$ fulfilled the criterion stated by Hatcher [32] and Bentler and Chou [12], demanding that the minimal number of subjects should be five times the number of free parameters in the model ${ }^{1}$. Similar sample sizes were also successfully used in other SEM studies [70]. Moreover, we used selected fit indices like the RMSEA and the CFI, which are less affected by sample size [61]. Nonetheless, the results

\footnotetext{
${ }^{1}$ As there are 14 free parameters in the accuracy and distortion model and 15 free parameters in the combinatory model, the minimal sample size is $\mathrm{N}=75$.
} 
should be interpreted with caution, and replication studies with larger samples are recommended.

Second, as this was a clinical study, mothers, teachers and therapists did not evaluate the child's behaviour in the same situation, but at home, in the kindergarten, and on admission to the Family Day Hospital. However, our analysis focussed on differences between mothers with and without psychopathology, which cannot be explained by situation-specific behaviour. Nevertheless, a replication in an experimental setting, with mothers, teachers and therapists evaluating exactly the same child behaviour, e. g. by use of videotaped material [40], might be useful to rule out possible effects of situation-specificity.

Third, this study focussed exclusively on the impact of maternal psychopathology on child behaviour ratings. Ideally, maternal psychopathology, like child psychopathology, should be assessed by multiple measures, e. g. self-report, interview, and report by others. For future studies, it would be helpful to establish an accepted way to measure maternal psychopathology, which would allow for the use of this important construct more frequently in other research contexts. Moreover, there are many other factors which may also influence the association between maternal psychopathology and child behaviour ratings, for instance maternal personality [58], previous experiences (memory effects) [21], or the use of different reference groups [59]. Depending on the specific circumstances, these effects may enlarge or outweigh the effects of maternal psychopathology. Future research with larger samples in standardized observation contexts and trained raters is needed to address multiple factors in one model.

\section{Conclusion}

The results of our study are in line with research on cross-informant agreement on child behaviour and psychopathology. The merits of our study are its integration of multiple perspectives and improved estimation of child psychopathology, recommendations for practitioners in child health services, and the use of maternal psychopathology as theoretical construct and as a moderator variable. 
First to say, there is no "gold standard" to assess child psychopathology. The actual accepted procedure is to consider each informant as a valuable source which contributes a considerable amount of information not accounted for by the others [1]. However, it remains unclear how the outcomes obtained from different informants, which may widely diverge in clinical contexts, should be integrated. The distortion model helps to explain differing results on the basis of parental psychopathology and also how to integrate multiple perspectives.

Second, for practitioners it may be important to know that the child behaviour ratings of a parent with severe psychopathology may be substantially biased. Consequently, when there are hints to the existence of psychopathology in a parent, clinicians should focus on the ratings of other informants, e. g., the other parent, or the kindergarten teacher. Furthermore, clinical assessment of children should always include a screening for parental psychopathology, for example with the Symptom Checklist-90-Revised or a short form of this measure, for example the BSI, the SCL-25 or the SCL-27 [46].

Turned the other way round, negative behaviour ratings may be seen as a serious sign of psychopathology not only in the child, but also in the parent who rated the child. Child therapists should bear this in mind when evaluating diagnostic information, and be aware that it may be the parent who (also) requires and merits professional help. This result should not be misunderstood in the sense that maternal ratings are discredited, but they should be used more carefully and in a more sophisticated way.

Third, our approach to assessing maternal psychopathology leads to two further issues. We extended the existing literature on the distortion-accuracy model by considering not only maternal depression, but by introducing maternal psychopathology as a general term to describe the distress of mothers, independent of their potential psychiatric diagnosis. This approach may stimulate more research around maternal psychopathology as a meaningful moderator variable, which may also play an important role in other contexts. In particular, more research is necessary to determine reliable cut-off scores for measures of parental psychopathology, and to develop algorithms to correct the potentially biased rating outcome of a parent with significant psychopathology. 


\section{References}

1. Achenbach TM (2006) As others see us. Clinical and research implications of crossinformant correlations for psychopathology Current Directions in Psychological Science 15:94-98

2. Achenbach TM, McConaughy SH, Howell CT (1987) Child/adolescent behavioural and emotional problems: Implications of cross-informant correlations for situational specifity. Psychological Bulletin 101:213-232

3. Achenbach TM, Rescorla LA (2000) Manual for the ASEBA preschool forms and profiles Burlington, VT: University of Vermont, Research Center for Children, Youth, \& Families

4. Akaike H (1987) Factor analysis and AIC. Psychometrika 52:317-332

5. Allison, PD (2003) Missing Data Techniques for Structural Equation Modeling. Journal of Abnormal Psychology 112(4): 545-557

6. Arbeitsgruppe Deutsche Child Behavior Checklist (2000) Elternfragebogen für Kleinund Vorschulkinder (CBCL/1.5-5). Arbeitsgruppe Kinder-, Jugend- und Familiendiagnostik (KJFD), Köln, Germany

7. Arbuckle JL (2006) Amos 70 User's Guide. Chicago, IL: SPSS Inc.

8. Averbeck-Holocher M, Furniss T, Postert C, Achtergarde S, Müller JM (2010) Child Psychiatric Family Day Hospital for Patients between 0 and 6 Years, Part II: Demographic Characteristics, Symptoms and Diagnoses in a Ten-Year-Interval Sample. Unpublished Manuscript

9. Beck AT, Steer RA (1987) Depression Inventory - Manual. San Antonio: The Psychological Corporation

10. Beck AT, Steer RA, Garbin MG (1988) Psychometric properties of the Beck Depression Inventory: Twenty-five years of evaluation. Clinical Psychology Review 8:77-100

11. Bentler PM (1990) Comparative fit indexes in structural models. Psychological Bulletin $107: 238-246$

12. Bentler PM, Chou CP (1987) Practical issues in structural modelling. Sociological Methods \& Research 16:78-117 
13. Bérube RL, Achenbach TM (2005) Bibliography of published studies using ASEBA instruments: 2005 edition. Burlington, VT: Research Center for Children, Youth, and Families, University of Vermont

14. Bingham CR, Loukas A, Fitzgerald HE, Zucker RA (2003) Parental ratings of son's behavior problems in high-risk families: Convergent validity, internal structure, and interparent agreement. Journal of Personality Assessment 80:237-251

15. Boyle MH, Pickles AR (1997) Influence of maternal depressive symptoms on ratings of childhood behaviour. Journal of Abnormal Child Psychology 25:399-412

16. Briggs-Gowan M, Carter AS, Skuban EM, McCue Horwitz S (2001) Prevalence of socialemotional and behavioural problems in a community sample of 1- and 2-year-old children. Journal of the American Academy of Child and Adolescent Psychiatry 40:811-819

17. Byrne B (2001) Structural equation modelling with AMOS. Mahwah, NJ: Erlbaum

18. Chi TC, Hinshaw SP (2002) Mother-child relationships of children with ADHD: The role of maternal depressive symptoms and depression-related distortions. Journal of Abnormal Child Psychology: An official publication of the International Society for Research in Child and Adolescent Psychopathology, 30(4): 387-400.

19. Chilcoat HD, Breslau N (1997) Does psychiatric history bias mothers' reports? An application of a new analytic approach. Journal of the American Academy of Child and Adolescent Psychiatry 36:971-979

20. Del Carmen-Wiggins R, Carter AS (2001) Assessment of infant and toddler mental health: Advances and challenges. Journal of the American Academy of Child and Adolescent Psychiatry 40:8-10

21. De Los Reyes A, Kazdin AE (2005) Informant discrepancies in the assessment of childhood psychopathology: A critical review, theoretical framework, and recommendations for study. Psychological Bulletin 131:483-509

22. Derogatis LR (1992) SCL-90-R, administration, scoring \& procedures manual-II for the (Revised) version and other instruments of the Psychopathology Rating Scale Series. Townson: Clinical Psychometric Research, Inc. 
23. Duhig AM, Renk K, Epstein MK, Phares V (2000) Interparental agreement on Internalizing, Externalizing, and Total Problems: A meta-analysis. Clinical Psychology: Science and Practice 7:435-453

24. Fan X, Wang L (1998) Effects of potential confounding factors on fit indices and parameter estimates for true and misspecified SEM models. Educational and Psychological Measurement 58:701-735

25. Fan X, Thompson B, Wang L (1999) Effects of sample size, estimation methods, and model specification on structural equation modeling fit indexes. Structural Equation Modeling: A Multidisciplinary Journal 6:56-83

26. Fergusson DM, Lynskey MT, Horwood LJ (1993) The effects of maternal depression on maternal ratings of child behavior. Journal of Abnormal Child Psychology 21:245-269

27. Ferro MA, Avison, WR, Campbell MK, Speechley, KN (2010) Do depressive symptoms affect mothers' reports of child outcomes in children with new-onset epilepsy? Quality of Life Research19(7):955-964

28. Gartstein MA, Bridgett DJ, Dishion TJ, Kaufman NK (2009) Depressed mood and maternal report of child behavior problems: Another look at the depression-distortion hypothesis. Journal of Applied and Development Psychology 30:149-160

29. German Society of Child and Adolescent Psychiatry, Psychosomatics and Psychotherapy (Ed.) (2007) Guide for Diagnosis and Therapy of Mental Diseases of Infants, Children, and Adolescents. [Deutsche Gesellschaft für Kinder- und Jugendpsychiatrie und Psychotherapie (Ed.) (2007) Leitlinien zur Diagnostik und Therapie von psychischen Störungen im Säuglings-, Kindes- und Jugendalter (3., überarb. Aufl.).] Köln: Deutscher Ärzte Verlag.

30. Grietens $H$, Onghena $P$, Prinzie $P$, Gadeyne $E$, Van Assche V, Ghesquière $P$, Hellinckx W (2004) Comparison of mothers', fathers', and teachers' reports on problem behavior in 5to 6-year-old children. Journal of Psychopathology and Behavioral Assessment 26:137-146 31. Haghighi F, Bach-Mizrachi H, Huang YY, Arango V, Shi S, Dwork AJ, Rosoklija G, Sheng HT, Morozova I, Ju J, Russo JJ, Mann JJ (2008) Genetic architecture of the human 
tryptophan hydroxylase 2 Gene: Existence of neural isoforms and relevance for major depression. Molecular Psychiatry 13:813-820

32. Hatcher $L$ (1994) A step-by-step approach to using the $S A S^{\circledR}$ system for factor analysis and structural equation modelling. Cary, NC: SAS Institute Inc.

33. Hautzinger M, Bailer M, Worall H, Keller F (1995) Beck-Depressions-Inventar (BDI). Testhandbuch (2. überarbeitete Auflage). Bern: Hans Huber

34. Hessel A, Schumacher J, Geyer M, Brähler E (2001) Symptom-Checkliste SCL-90-R: Testtheoretische Überprüfung und Normierung an einer bevölkerungsrepräsentativen Stichprobe. Diagnostica 47:27-39

35. Hood KK (2009) The influence of caregiver depressive symptoms on proxy report of youth depressive symptoms: A test of the depression-distortion hypothesis in pediatric type 1 diabetes. Journal of Pediatric Psychology, 34(3):294-303

36. Hu L-T, Bentler PM (1995) Evaluating model fit. In RH Hoyle (ed), Structural equation modelling: Concepts, issues, and applications (pp 76-99). Thousand Oaks, CA: Sage

37. Hu L-T, Bentler PM (1999) Cutoff criteria for fit indexes in covariance structure analysis: Conventional criteria versus new alternatives. Structural Equation Modeling: A Multidisciplinary Journal 6:1-55

38. Hutzelmeyer-Nickels A, Noterdaeme M (2007) Usefulness of the Child Behavior Checklist (CBCL 1 1/2-5) in the assessment of preschool children with developmental problems. Praxis der Kinderpsychologie und Kinderpsychiatrie 56:573-588

39. Kerr DCR, Lunkenheimer ES, Olson SL (2007) Assessment of child problem behaviors by multiple informants: a longitudinal study from preschool to school entry. Journal of Child Psychology and Psychiatry 48:967-975

40. Kroes G, Veerman JW, De Bruyn EEJ (2003) Bias in parental reports? Maternal psychopathology and the reporting of problem behaviour in clinic-referred children. European Journal of Psychological Assessment 19:195-203 
41. Kroes G, Veerman, JW, De Bruyn EEJ (2004) The impact of the Big Five personality traits on reports of child behaviour problems by different informants. Journal of Abnormal Child Psychology 33:231-240

42. Kuschel A, Heinrichs N, Bertram H, Naumann S, Hahlweg K (2007) Wie gut stimmen Eltern und Erzieherinnen in der Beurteilung von Verhaltensproblemen bei Kindergartenkindern überein? [How well do parents' and teacher's reports agree on behavior problems in preschool aged children?] Zeitschrift für Kinder- und Jugendpsychiatrie und Psychotherapie 35:51-58

43. Lambert MC, Lyubansky M, Achenbach TM (1998) Behavioral and emotional problems among adolescents of Jamaica and the United States: Parent, teacher, and self-reports for ages 12 to 18. Journal of Emotional and Behavioral Disorders 6:180-187

44. Lee L-C, Huang K-Y, Halpern CT, Newschaffer CJ (2007) The impact of maternal depression on developmental psychopathology during early childhood. In AM Columbus (ed), Advances in psychology research Vol. 49 (pp 81-106) Hauppauge, NY, US: Nova Science Publishers

45. Mick E, Santangelo, SL, Wypij D, Biederman J (2000) Impact of maternal depression on ratings of comorbid depression in adolescents with attention-deficit/hyperactivity disorder. Journal of the American Academy of Child \& Adolescent Psychiatry, 39(3):314-319.

46. Müller JM, Postert C Furniss T, Beyer T, Achtergarde S (2010) Comparison of eleven short forms of the Symptom Checklist Revised (SCL -90-R). Journal of Psychopathology and Behavioral Assessment 32(2):246-254

47. Najman JM, Williams GM, Nikles J, Spence S, Bor W, O’Callaghan M, Le Brocque R, Andersen MJ (2000) Mothers' mental illness and child behaviour problems: Cause-effect association of observational bias? Journal of the American Academy of Child and Adolescent Psychiatry 39:92-602

48. Ohrt T, Sjodin I, Thorell L-H (1999) Cognitive distortions in panic disorder and major depression: Specificity for depressed mood. Nordic Journal of Psychiatry 53:459-464

49. Olsson A, Phelps EA (2007) Social learning of fear. Nature Neuroscience 10:1095-1102 
50. Pfeiffer JS (1997) Teacher and direct care staff ratings of psychopathology among adolescents with mental retardation in a residential facility. Dissertation Abstracts International, Section B: The Sciences and Engineering 57 (11-B):7234

51. Phares V (1997) Accuracy of informants: Do parents think that mother knows best? Journal of Abnormal Child Psychology 25:165-171

52. Pilowsky DJ, Wickramaratne PJ, Rush AJ, Hughes CW, Garber J, Malloy E, King CA, Cerda G, Sood AB, Alpert JE, Wisniewski SR, Trivedi MH, Talati A, Carlson MM, Liu HH, Fava M, Weissman MM (2006) Children of currently depressed mothers: A STAR*D ancillary study. Journal of Clinical Psychiatry 67:126-136

53. Postert C, Averbeck-Holocher M, Beyer T, Müller J, Fürniss T (2009). Five systems of psychiatric classification for preschool children: Do differences in validity, usefulness and reliability make for competitive or complimentary constellations? Child Psychiatry and Human Developmen, 40:25-41

54. Renk K (2005) Cross-informant ratings of the behaviour of children and adolescents: The "gold standard". Journal of Child and Family Studies 14:457-468

55. Rescorla LA (2005) Assessment of young children using the Achenbach System of Empirically Based Assessment (ASEBA). Mental Retardation and Developmental Disabilities Research Reviews 11:226-237

56. Richter P, Werner J, Heerlein A, Kraus A, Sauer H (1998) On the validity of the Beck Depression Inventory. Psychopathology 31:160-168

57. Richters JE (1992) Depressed mothers as informants about their children: A critical review of the evidence for distortion. Psychological Bulletin 112:485-499

58. Roa Capilla ML, Del Barrio Gandara MV (2003) Maternal personality: Children's problem implication. Revista Iberoamericana de Diagnostico y Evaluacion Psicologica 16:53-69

59. Saudino KJ, Ronald A, Plomin R (2005) The etiology of behaviour problems in 7-yearold twins: Substantial genetic influence and negligible shared environmental influence for parent ratings and ratings by same and different teachers. Journal of Abnormal Child Psychology 33:113-130 
60. Schauenburg H, Strack M (1998) Die Symptom-Checklist-90-R von statistischen und klinisch signifikanten Psychotherapieergebnissen Psychotherapie, Psychosomatik, Medizinische Psychologie 48:257-264

61. Schermelleh-Engel K, Moosbrugger H, Müller H (2003) Evaluating the fit of structural equation models: Tests of significance and descriptive goodness-of-fit-measures. Methods of Psychological Research Online 8:23-74

62. Sourander A, Piha J (1997) Parent, teacher and clinical ratings on admission to child psychiatric inpatient treatment: A study of cross-informant correlations using the CBCL, Rutter scales and the CGAS. Nordic Journal of Psychiatry 51:365-370

63. Task Force on Research Diagnostic Criteria: Infancy and Preschool (2003) Research diagnostic criteria for infants and preschool children: the process and empirical support. Journal of the American Academy of Child and Adolescent Psychiatry 42:1504-1512

64. Thompson MP, Kaslow NJ, Kingree JB, King M, Bryant L Jr, Rey M (1998) Psychological symptomatology following parental death in a predominantly minority sample of children and adolescents. Journal of Clinical Child Psychology 27:434-441

65. Trapolini T, Ungerer JA, McMahon CA (2008) Maternal depression: Relations with maternal caregiving representations and emotional availability during the preschool years. Attachment \& Human Development 10:73-90

66. Treutler CM, Epkins CC (2003) Are discrepancies among child, mother, and father reports on children's behavior related to parents' psychological symptoms and aspects of parent-child-relationships? Journal of Abnormal Child Psychology 31:13-27

67. Vallejo MA, Jordan CM, Diaz MI, Comeche MI, Ortega J (2007) Psychological assessment via the internet: A reliability and validity study of online (vs paper and pencil) versions of the General Health Questionnaire-28 (GHQ-28) and the Symptom-Checklist-90Revised (SCL-90-R). Journal of Medical Internet Research 9:1-10

68. Van Zeijl J, Mesman J, Stolk MN, Alink LRA, Van ljzendoorn MH, BakermansKranenburg MJ, Juffer F, Koot HM (2006) Terrible ones? Assessment of externalizing 
behaviours in infancy with the Child Behavior Checklist. Journal of Child Psychology and Psychiatry 47:801-810

69. Vierhaus M, Lohaus A (2008) Children and parents as informants of emotional and behavioural problems predicting female and male adolescent risk behaviour: A longitudinal cross-informant study. Journal of Youth and Adolescence 37:211-224

70. Von Eye A, Spiel C, Wagner P (2003) Structural equations modeling in developmental research: Concepts and applications. Methods of Psychological Research Online 8:75-112

71. Von Hofacker N, Papoušek M (1998) Disorders of excessive crying, feeding, and sleeping: The Munich Interdisciplinary Research and Intervention Program. Infant Mental Health Journal 19:180-201

72. Wheaton B, Muthén B, Alwin DF, Summers GF (1977) Assessing reliability and stability in panel models. In DR Heise (ed), Sociological methodology 1977 (pp 84-136). San Francisco: Jossey-Bass

73. Xing Tan T, Dedrick RF, Marfo K (2007) Factor Structure and Clinical Implications of Child Behavior Checklist/1.5-5 Ratings in a Sample of Girls Adopted from China. Journal of Pedriatic Psychology 32:807-818

74. Youngstrom E, Izard C, Ackerman B (1999) Dysphoria-related bias in maternal ratings of children. Journal of Consulting and Clinical Psychology 67:905-916

75. Youngstrom E, Loeber R, Strouthamer-Loeberm M (2000) Patterns and correlates of agreement between parents, teacher, and male adolescent ratings of externalizing and internalizing problems. Journal of Consulting and Clinical Psychology 68:1038-1050 76. Zero to Three (2005) DC: 0-3R Diagnostic classification of mental health and developmental disorders of infancy and early childhood: revised edition. Washington DC: Zero to Three

Table 1 Cross-informant discrepancies (CIS mean scores) on CBCL and C-TRF broadband scales between mothers, kindergarten teachers, and therapists 


\begin{tabular}{|c|c|c|c|c|}
\hline & Mother & Therapist & \multicolumn{2}{|c|}{ Paired t-test } \\
\hline & Mean \pm SD & Mean \pm SD & $\mathrm{t}(77)$ & $p$ \\
\hline Internalizing & $14.62 \pm 7.73$ & $12.24 \pm 7.08$ & 2.12 & .037 \\
\hline Externalizing & $23.40 \pm 9.31$ & $15.10 \pm 10.53$ & 6.88 & .000 \\
\hline \multirow[t]{3}{*}{ Total Problems } & $50.00 \pm 18.62$ & $36.04 \pm 17.34$ & 5.23 & .000 \\
\hline & Mother & Teacher & \multicolumn{2}{|c|}{ Paired t-test } \\
\hline & Mean \pm SD & Mean \pm SD & $\mathrm{t}(74)$ & $p$ \\
\hline Internalizing & $14.92 \pm 7.10$ & $12.49 \pm 8.62$ & 2.35 & .022 \\
\hline Externalizing & $23.97 \pm 9.24$ & $18.40 \pm 10.78$ & 4.99 & .000 \\
\hline \multirow[t]{3}{*}{ Total Problems } & $50.87 \pm 18.73$ & $40.17 \pm 21.82$ & 4.08 & .000 \\
\hline & Teacher & Therapist & \multicolumn{2}{|c|}{ Paired t-test } \\
\hline & Mean \pm SD & Mean \pm SD & $\mathrm{t}(60)$ & $p$ \\
\hline Internalizing & $12.40 \pm 8.35$ & $12.11 \pm 6.74$ & -0.21 & n.s. \\
\hline Externalizing & $18.21 \pm 11.40$ & $15.51 \pm 10.57$ & -1.94 & n.s. \\
\hline Total Problems & $39.83 \pm 22.53$ & $35.91 \pm 16.54$ & -1.19 & n.s. \\
\hline
\end{tabular}


Table 2 Psychometric properties of observed variables for structural equation modeling

\begin{tabular}{lccccc}
\hline & $\begin{array}{c}\text { Cronbach's } \\
\text { Alpha }\end{array}$ & BDI & $\begin{array}{c}\text { SCL- } \\
\text { GSI }\end{array}$ & $\begin{array}{c}\text { Total } \\
\text { Problems }\end{array}$ & $\begin{array}{c}\text { Potal } \\
\text { Problems } \\
\text { BDI }\end{array}$ \\
SCL-GSI & .86 & & & & \\
Total Problems score Mother & .96 & $.74^{* * *}$ & & \\
Total Problems score Teacher & .90 & $.34^{* * *}$ & $.42^{* * *}$ & \\
Total Problems score Therapist & .94 & .12 & .06 & $.38^{* * *}$ & \\
\hline
\end{tabular}

Note: $\mathrm{BDI}=$ Beck's Depression Inventory; SCL-GSI = Global Severity Index form the Symptom Checklist-90-Revised

${ }^{*} \mathrm{p}<.05,{ }^{* *} \mathrm{p}<.01,{ }^{* * *} \mathrm{p}<.001$ 
Table 3 Model fit of combinatory, accuracy and distortion model

\begin{tabular}{|l|c|c|c|c|c|c|}
\hline & \multicolumn{2}{|c|}{ Distortion model } & \multicolumn{2}{c|}{ Accuracy model } & \multicolumn{2}{c|}{ Combinatory model } \\
\hline & \multicolumn{2}{|c|}{$\mathrm{df}=6$} & \multicolumn{2}{c|}{$\mathrm{df}=6$} & \multicolumn{2}{c|}{$\mathrm{df}=5$} \\
\hline${ }^{2}(\mathrm{p})$ & 4.26 & $(.642)$ & 13.71 & $(.033)$ & 4.16 & $(.527)$ \\
\hline${ }^{2} / \mathrm{df}$ & 0.71 & & 2.28 & & 0.83 & \\
\hline CFI & 1.00 & & .91 & & 1.00 & \\
\hline RMSEA & .000 & & 0.102 & & .000 & \\
\hline AIC & 32.26 & & 41.71 & & 34.16 & \\
\hline
\end{tabular}

Note: $\mathrm{CFI}=$ Comparative Fit Index: RMSEA $=$ Root Mean Square Error of Approximation; AIC = Akaike Information Criterion.
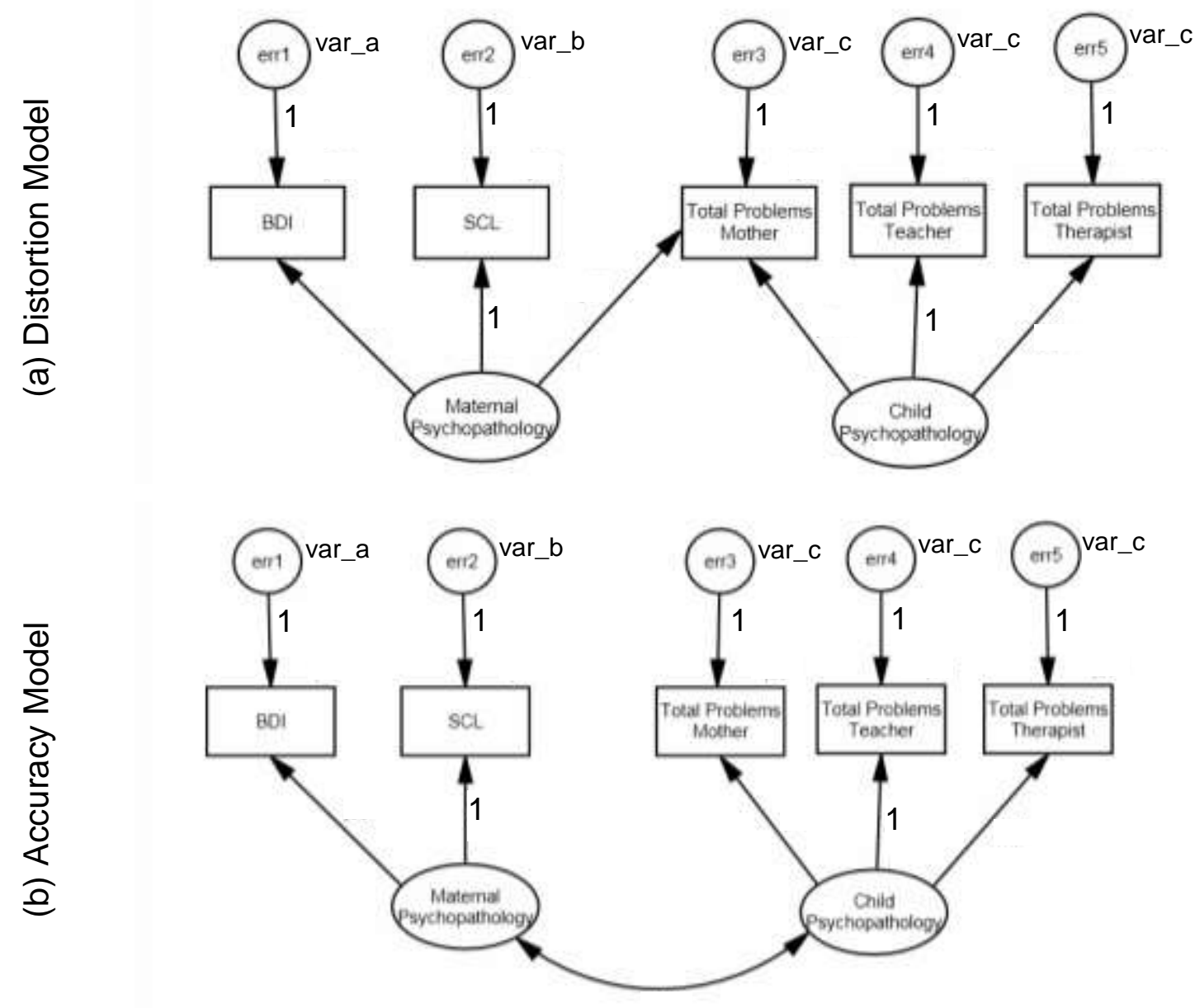


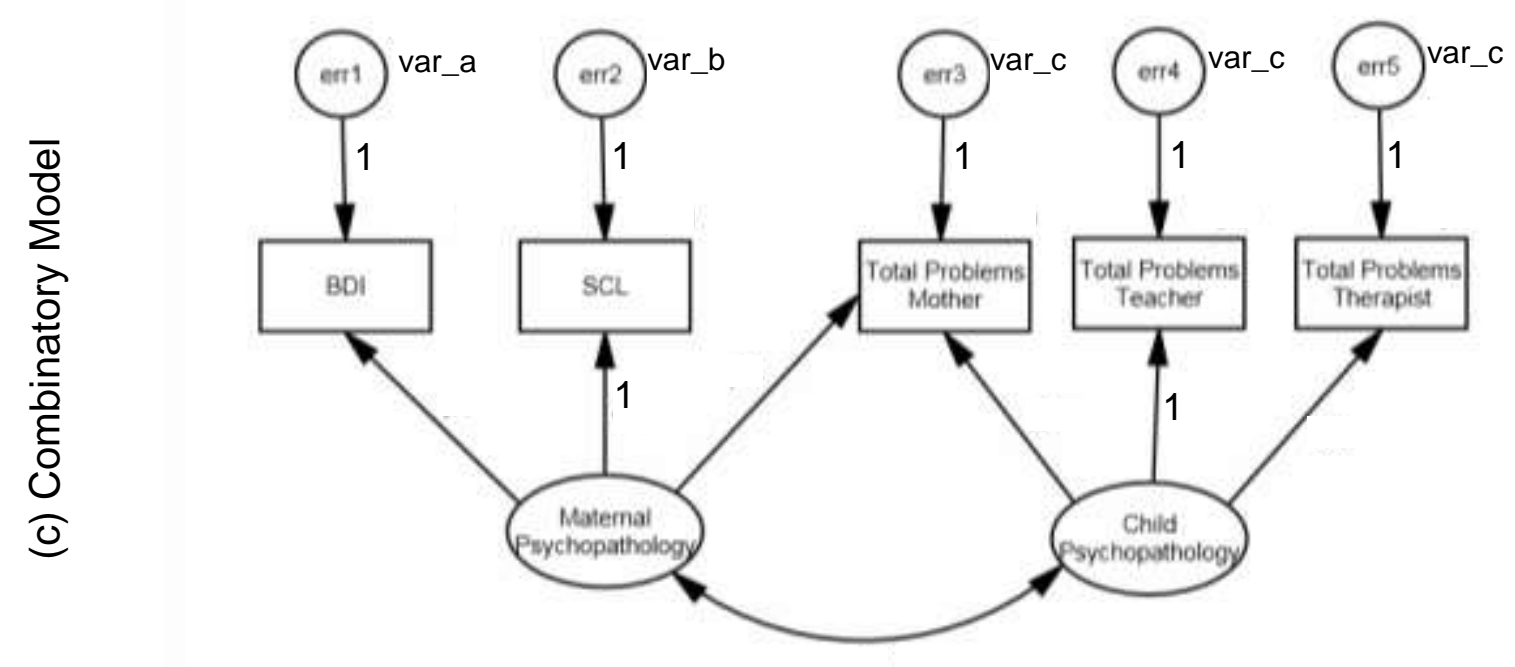

Fig. 1a,b,c Hypothesized associations between maternal psychopathology (latent factor), child psychopathology (latent factor), and five manifest variables (BDI scores, SCL scores, and CROSS-INFORMANT SYNDROME Total Problems scores rated by mother, teacher and therapist), which are the basis of the structural equation model of (a) distortion model, (b) accuracy model, and (c) combinatory model. Variables in circles represent error/residual terms. For model details see text. 

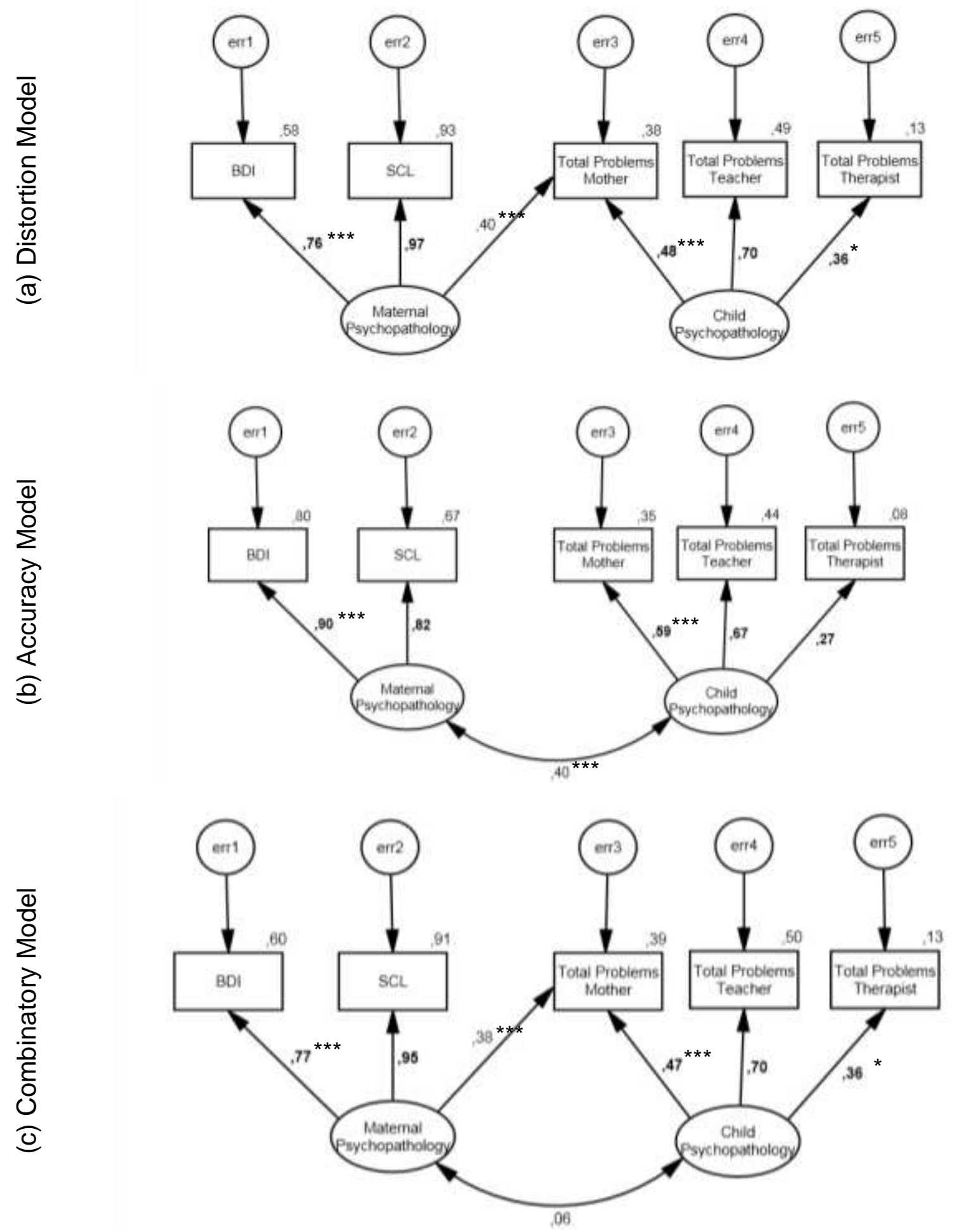

Fig. 2a,b,c Output diagram displaying standardized regression weights (path coefficients) between maternal psychopathology (latent factor), child psychopathology (latent factor), and five manifest variables (BDI scores, SCL scores, and CIS Total Problem scores rated by mother, teacher and therapist) in (a) the distortion model, (b) the accuracy model, and (c) the combinatory model. 
